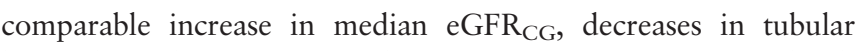
biomarkers (beta-2 microglobulin/creatinine ratio, retinol binding protein/creatinine ratio), increases in mean percent change in hip and spine BMD, and decreases in bone turnover markers (C-type collagen sequence, procollagen type $1 \mathrm{~N}$-terminal propeptide) were observed among patients previously treated with $<4$ and $\geq 4$ years of TDF, respectively (table 1 ). Changes in fasting lipid parameters were not influenced by treatment duration.

Conclusions In virally suppressed patients on TDF a median of 4 years who switched to TAF treatment, improvements in bone and renal parameters and changes in fasting lipids were not impacted by prior duration of TDF use.

Abstract IDDF2020-ABS-0060 Table 1 Renal, bone and fasting lipid parameters in patients previously treated with $<4$ or $\geq 4$ years of TDF before switching to TAF

\begin{tabular}{|c|c|c|c|}
\hline & $<4$ years & $\geq 4$ years & $\mathrm{p}$-value \\
\hline & $\mathrm{n}=105$ & $\mathrm{n}=138$ & \\
\hline \multicolumn{4}{|l|}{ Renal parameters } \\
\hline $\begin{array}{l}\text { Serum creatinine, median (Q1, } \\
\text { Q3) change, mg/dL }\end{array}$ & $0(-0.04,0.05)$ & $0(-0.06,0.05)$ & 0.78 \\
\hline $\begin{array}{l}\text { eGFR }_{\mathrm{CG}} \text {, median (Q1, Q3) } \\
\text { change, } \mathrm{mL} / \mathrm{min}^{3}\end{array}$ & $+0.87(-3.96,6.01)$ & $+1.03(-4.64,7.21)$ & 0.95 \\
\hline $\begin{array}{l}\geq 1 \text { stage improvement in CKD } \\
\text { stage, } \mathrm{n}(\%)\end{array}$ & $11 / 46(23.9)$ & $17 / 66(25.8)$ & 0.26 \\
\hline $\begin{array}{l}\geq 1 \text { stage worsening in CKD } \\
\text { stage, } \mathrm{n}(\%)\end{array}$ & $3 / 99(3.0)$ & $12 / 135(8.9)$ & \\
\hline $\begin{array}{l}\text { Urine biomarkers, median (Q1, } \\
\text { Q3)\% change }\end{array}$ & & & \\
\hline Protein/creatinine ratio, mg/g & $-14.6(-44.0,37.4)$ & $-9.9(-45.5,32.6)$ & 0.97 \\
\hline Albumin/creatinine ratio, mg/g & $+5.5(-24.1,41.5$ & $-5.8(-37.0,29.7)$ & 0.08 \\
\hline $\begin{array}{l}\text { Retinol binding protein/ } \\
\text { creatinine ratio, } \mu g / g\end{array}$ & $-15.8(-39.1,15.2)$ & $-17.8(-43.0,18.4)$ & 0.67 \\
\hline $\begin{array}{l}\text { Beta-2 microglobulin/creatinine } \\
\text { ratio, } \mu g / g\end{array}$ & $-36.0(59.4,2.2)$ & $-36.1(-64.4,-2.8)$ & 0.75 \\
\hline Bone parameters & & & \\
\hline Hip $B M D^{b}$, mean (SD)\% change & $+0.69(1.828)$ & $+0.64(2.263)$ & 0.84 \\
\hline $\begin{array}{l}\text { Spine BMD, mean (SD)\% change } \\
\text { Serum bone biomarkers, median } \\
(\mathrm{Q} 1, \mathrm{Q}) \% \text { change }\end{array}$ & $+1.84(3.04)$ & $+1.67(3.76)$ & 0.71 \\
\hline $\begin{array}{l}\text { C-type collagen sequence (CTX), } \\
\mathrm{ng} / \mathrm{mL} \text { [resorption] }\end{array}$ & $-29.8(-45.8,-14.0)$ & $-28.8(-42.8,-15.3)$ & 0.57 \\
\hline $\begin{array}{l}\text { Procollagen type } 1 \mathrm{~N} \text {-terminal } \\
\text { propeptide (P1NP), ng/mL } \\
\text { [formation] }\end{array}$ & $-20.4(-37.5,-7.4)$ & $-17.7(-29.6,-8.5)$ & 0.16 \\
\hline $\begin{array}{l}\text { Parathyroid hormone, } \mathrm{pg} / \mathrm{mL} \\
\text { (PTH) [metabolism] }\end{array}$ & $-9.4(-27.6,16.4)$ & $-13.4(-32.5,6.8)$ & 0.07 \\
\hline Fasting Lipid parameters & & & \\
\hline $\begin{array}{l}\text { Total cholesterol, median (Q1, } \\
\text { Q3) change, mg/dL }\end{array}$ & $20(6,31)$ & $19(5,33)$ & 0.93 \\
\hline $\begin{array}{l}\text { Total cholesterol/HDL, median } \\
\text { (Q1, Q3) change, mg/dL }\end{array}$ & $0.1(-0.2,0.4)$ & $0.3(-0.1,0.5)$ & 0.08 \\
\hline $\begin{array}{l}\mathrm{HDL} \text {, median }(\mathrm{Q} 1, \mathrm{Q} 3) \text { change, } \\
\mathrm{mg} / \mathrm{dL}\end{array}$ & $4(0,8)$ & $3(-2,7)$ & 0.13 \\
\hline $\begin{array}{l}\text { LDL, median (Q1, Q3) change, } \\
\mathrm{mg} / \mathrm{dL}\end{array}$ & $17(5,27)$ & $15(5,27)$ & 0.54 \\
\hline $\begin{array}{l}\text { Triglycerides, median (Q1, Q3) } \\
\text { change, mg/dL }\end{array}$ & $13(-5,41)$ & $17(-1,46)$ & 0.22 \\
\hline
\end{tabular}

${ }^{a}$ eGFR in creatinine clearance (Cockcroft-Gault method); ${ }^{b}$ BMD is bone mineral density by DXA scan
IDDF2020-ABS-0061 IMPACT OF TREATMENT WITH TENOFOVIR ALAFENAMIDE (TAF) OR TENOFOVIR DISOPROXIL FUMARATE (TDF) ON HEPATOCELLULAR CARCINOMA (HCC) INCIDENCE IN PATIENTS WITH CHRONIC HEPATITIS B (CHB)

${ }^{1}$ Henry Lik Yuen Chan* ${ }^{2}$ Young-Suk Lim, ${ }^{3}$ Wai Kay Seto, ${ }^{4}$ Qin Ning, ${ }^{5}$ Kosh Agarwal, ${ }^{6}$ Harry LA Janssen, ${ }^{7}$ Calvin 0 Pan, ${ }^{8}$ Wan Long Chuang, ${ }^{9}$ Namiki Izumi, ${ }^{10}$ Scott Fung, ${ }^{11}$ Shalimar, ${ }^{12}$ Maurizia Brunetto, ${ }^{13}$ John Flaherty, ${ }^{13}$ Shuyuan Mo, ${ }^{13}$ Cong Cheng, ${ }^{13}$ Lanjia Lin, ${ }^{13}$ Anuj Gaggar, ${ }^{13}$ Mani Subramanian, ${ }^{14}$ Patrick Marcellin, ${ }^{15}$ Edward Gane, ${ }^{16}$ Jinlin Hou,

${ }^{17}$ Maria Buti. ${ }^{1}$ Institute of Digestive Disease, Department of Medicine and Therapeutics, and State Key Laboratory of Digestive Disease, The Chinese University of Hong Kong, Hong Kong: ${ }^{2}$ Asan Medical Center, University of Ulsan College of Medicine, Korea, South; ${ }^{3}$ University of Hong Kong, Hong Kong; ${ }^{4}$ Tongji Hospital, Tongji Medical College, China; ${ }^{5}$ Kings College Hospital, UK; ${ }^{6}$ Toronto Western Hospital, Canada; ${ }^{7}$ NYU Langone Medical Center, NYU School of Medicine, New York, USA; ${ }^{8}$ Kaohsiung Medical University Hospital, Kaohsiung Medical University, Taiwan; ${ }^{9}$ Musashino Red Cross Hospital, Japan; ${ }^{10}$ Toronto General Hospital, Canada; ${ }^{11}$ All India Institute of Medical Sciences, India; ${ }^{12}$ University of Pisa, Pisa, Italy; ${ }^{13}$ Gilead Sciences, Foster City, USA; ${ }^{14}$ Hôpital Beaujon, France; ${ }^{15}$ Auckland Clinical Studies, Auckland, New Zealand; ${ }^{16}$ Nanfang Hospital of Southern Medical University, China; ${ }^{17}$ Hospital Universitario Valle Hebron, Spain

\subsection{6/gutjn-2020-IDDF.144}

Background Potent antivirals can reduce HCC incidence in CHB. TDF and TAF are first-line treatments, and in Phase 3 studies through 3 years, TAF has shown antiviral efficacy similar to TDF, higher rates of ALT normalization, and no resistance. We evaluated HCC incidence in patients participating in these ongoing studies.

Methods HBeAg-positive $(n=1039)$ and -negative $(n=593)$ patients with HBV DNA 20,000 IU/mL and ALT $>60 \mathrm{U} / \mathrm{L}$ (males) or $>38 \mathrm{U} / \mathrm{L}$ (females) were randomized $(2: 1)$ to TAF $25 \mathrm{mg}$ QD or TDF $300 \mathrm{mg}$ QD for up to 3 years, followed

Abstract IDDF2020-ABS-0061 Table 1 Observed vs predicted incidence of HCC in CHB patients treated with TAF or TDF through week 192 in 2 Phase 3 trials

\begin{tabular}{|c|c|c|c|c|c|}
\hline \multirow[t]{2}{*}{ Time Interval (Day) } & \multirow{2}{*}{$\begin{array}{l}\text { Observed } \\
\text { Cases }\end{array}$} & \multirow{2}{*}{$\begin{array}{l}\text { Predicted } \\
\text { Cases }\end{array}$} & \multirow{2}{*}{$\begin{array}{l}\text { Standard } \\
\text { Incidence Ratio } \\
\text { (SIR) }\end{array}$} & \multicolumn{2}{|l|}{$95 \% \mathrm{Cl}$} \\
\hline & & & & $\begin{array}{l}\text { Lower } \\
\text { bound }\end{array}$ & $\begin{array}{l}\text { Upper } \\
\text { bound }\end{array}$ \\
\hline$(0,105]$ & 1 & 2.6 & 0.38 & 0.053 & 2.695 \\
\hline$(0,174]$ & 2 & 4.4 & 0.46 & 0.115 & 1.836 \\
\hline$(0,180]$ & 3 & 4.5 & 0.67 & 0.215 & 2.065 \\
\hline$(0,253]$ & 4 & 6.3 & 0.63 & 0.238 & 1.690 \\
\hline$(0,378]$ & 5 & 9.5 & 0.53 & 0.220 & 1.267 \\
\hline$(0,392]$ & 6 & 9.9 & 0.60 & 0.271 & 1.343 \\
\hline$(0,401]$ & 7 & 10.2 & 0.68 & 0.326 & 1.434 \\
\hline$(0,460]$ & 8 & 12.1 & 0.66 & 0.329 & 1.317 \\
\hline$(0,675]$ & 9 & 19.0 & 0.47 & 0.246 & 0.908 \\
\hline$(0,729]$ & 10 & 20.8 & 0.48 & 0.259 & 0.895 \\
\hline$(0,747]$ & 11 & 21.0 & 0.52 & 0.290 & 0.946 \\
\hline$(0,854]$ & 12 & 22.3 & 0.54 & 0.305 & 0.947 \\
\hline$(0,855]$ & 13 & 22.3 & 0.58 & 0.338 & 1.003 \\
\hline$(0,1209]$ & 14 & 28.7 & 0.49 & 0.289 & 0.825 \\
\hline$(0,1370]$ & 15 & 32.9 & 0.46 & 0.275 & 0.756 \\
\hline$(0,1534]$ & 16 & 34.9 & 0.46 & 0.281 & 0.749 \\
\hline $\begin{array}{l}\text { (0, Max observed } \\
\text { time at Week 192] }]^{\dagger}\end{array}$ & 16 & 35.3 & 0.45 & 0.278 & 0.740 \\
\hline
\end{tabular}

* $\mathrm{SIR}$ is Standardized Incidence Ratio for observed cases vs predicted cases based on the REACH-B model.

The maximum observed time at Week 192 for each subject included in the analysis. 
by open-label TAF through Year 8. Patients with hepatic decompensation, co-infection with $\mathrm{HCV} / \mathrm{HDV} / \mathrm{HIV}$, or evidence of HCC were excluded. HCC was assessed at 6 monthly intervals by hepatic ultrasonography beginning after Week 96 and by local standards of care. The standardized incidence ratio (SIR) for HCC was calculated for observed cases relative to predicted cases using the REACH-B model.

Results 1632 patients were followed for up to 4 years; HCC was seen in 16 patients $(0.98 \%$; 7 TAF; 9 TDF); median time to onset was 568 days. At baseline HCC patients were older (median age 53 vs $40 \mathrm{y} ; \mathrm{p}<0.001$ ), had lower median HBV DNA (6.2 vs $\left.7.3 \log _{10} \mathrm{IU} / \mathrm{mL} ; \mathrm{p}=0.041\right)$ and were more likely to have cirrhosis (FibroTest score $0.75 ; 31 \%$ vs $10 \%$; $\mathrm{p}=0.004$ ). For study patients, the overall SIR was significantly reduced with TAF or TDF treatment 0.45 (95\% CI $0.278-0.740)$ (table 1). HCC incidence was significantly reduced (SIR 0.42, 95\% CI 0.23 to 0.75 ) in noncirrhotic patients ( $n=11$ vs 26.5 predicted), but not for cirrhotic patients ( $n=5$ vs 8.1 predicted). The SIR was significantly reduced in noncirrhotic patients receiving TAF $(n=5)$, but not in those with TDF $(n=6)$.

Conclusions In $\mathrm{CHB}$ patients treated with TAF or TDF for up to 4 years, HCC incidence was reduced, particularly in noncirrhotic patients. Additional follow up is needed to further characterize the impact of longer-term treatment on HCC risk reduction.

\section{IDDF2020-ABS-0062 EXPLORATORY DATA ANALYSIS OF MIMIC- III DATABASE AND PREDICTING MORTALITY OF ACUTE HEPATIC FAILURE}

Yi Yu*. Department of Critical Care Medicine, the Second Affiliated Hospital of Guangzhou University of Chinese Medicine, China

\subsection{6/gutjnl-2020-IDDF.145}

Background Using MIMIC-III database to establish a machine learning method to predict the risk prediction model of mortality in patients with acute hepatic failure, assisting clinicians in clinical decision making.

Methods We collected the demographics, physiological and biochemical parameters of the patients 24 hours before admission, and the variability and dynamic characteristics contained in the target patient as explanatory variables. In-hospital mortality was used as an outcome variable. Excellent machine learning algorithms such as random forest, xgboost, etc. were used to establish classification models to predict the severity of the acute hepatic failure.

Results The proportion of diseases of different systems changing with age was obtained, and the characteristics of the disease spectrum in MIMIC-III database were explored and interpreted. In 1,037 patients with acute hepatic failure, the optimal AUC of prediction models established using random forest and xgboost machine learning algorithms reached 0.88 $[0.86,0.90]$, which outperformed traditional SOFA and SAPS clinical scores.

Conclusions The performance of the model is better than the traditional clinically used scores. It can help clinicians to identify patients' risk of deterioration and death early. Clinical decision-making provides supports and can be used as a reference for developing next-generation disease severity scores. The application of analytics based on big data in the medical field provides us with more reliable technical means for understanding the development process, early diagnosis, and clinical decision support.

\section{IDDF2020-ABS-0063}

\section{UNRESECTABLE HEPATOCELLULAR CARCINOMA: TRANSCATHETER ARTERIAL CHEMOEMBOLIZATION COMBINED WITH MICROWAVE ABLATION VERSUS COMBINED WITH CRYOABLATION}

Jialiang Wei*, Jiaping Li, Wenzhe Fan. Department of Interventional Oncology, the First Affiliated Hospital, Sun Yat-sen University, China

\subsection{6/gutjnl-2020-IDDF.146}

Background Transcatheter arterial chemoembolization (TACE) combined with ablation has been widely used for treating unresectable hepatocellular carcinoma (HCC). However, the technique with which TACE should be combined for it to be more effective remains unknown. To evaluate the efficacy and
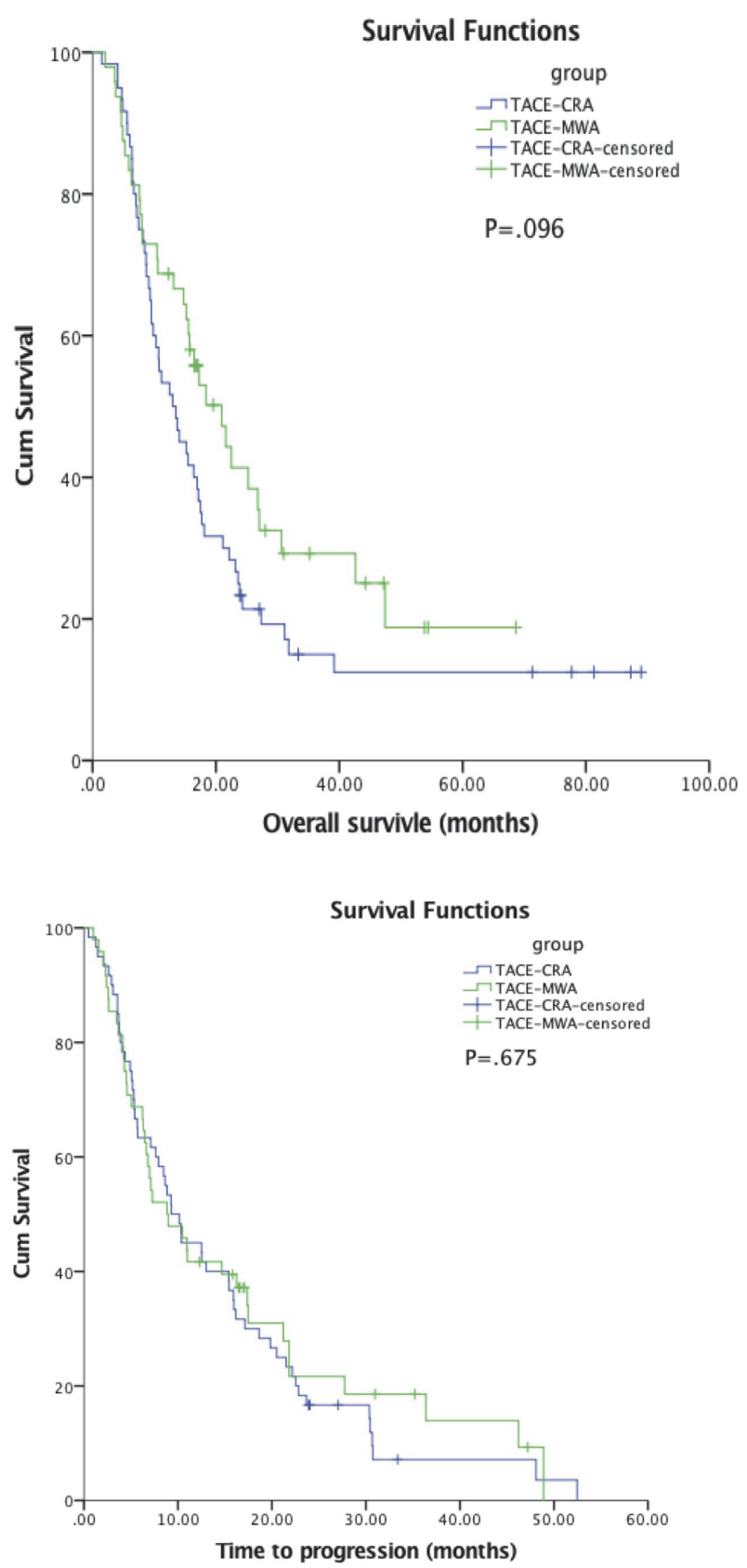

Abstract IDDF2020-ABS-0063 Figure 1 Kaplan-Meier curves of OS \& TTP 